\title{
Treating Health Care:
How the Canadian System Works and How It Could Work Better
}

\author{
By Raisa B. Deber
}

Reviewed by Jennifer Zwicker

\section{Abstract}

Health policy analysis requires an understanding of a broad range of topics that are often taught in different disciplines spanning economics, political science, ethics, health administration, public health and healthcare. Professor Raisa Deber's Treating Health Care is essential reading for anyone interested in understanding the basic fundamentals of the healthcare system, eloquently weaving together key concepts across disciplines and background information to equip the reader with a "toolkit" for decision making in health policy analysis.

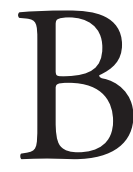

y nature, health policy is a multidisciplinary space occupied by stakeholders with a range of interests and training. This can create a disconnect because policy is where providers, payers, patients and decision makers (many of whom wear several of these "hats" at different times) must work together toward common health policy goals.

Fundamentally, health policy questions are about tradeoffs. There is no right or wrong answer, but at a minimum, decisions need to be made systematically, based on common values. Without common values and guiding frameworks agreed upon and understood, the complex and diverse decisions that

health policy impacts can quickly become fragmented and easily influenced. This is not a problem unique to Canada, but the role of fiscal federalism and Canada Health Act legislation provide a distinct lens to decision making that requires a madein-Canada approach.

Few understand this Canadian health policy context better than Professor Raisa Deber, who has had a career as a teacher and researcher committed to using health policy analysis to strengthen publicly funded Medicare. In Treating Health Care, Professor Deber distinguishes advocacy from analysis, noting that while both are important, the analysis-based perspective she presents aims to clarify how likely it is that a specific approach would achieve identified goals.

Connecting theory to practice is arguably one of the greatest struggles in Canadian health policy. The traditional theoretical approach Professor Deber reviews relies on well-established and accepted definitions and frameworks. Policy is defined simply as, "a set of interrelated decisions taken by a political actor or group of actors concerning the selection of goals and the means of achieving them within a specified situation where the decisions should, in principle, be within the power of these actors to achieve." As evident from the struggle to implement 
numerous commissioned reports for healthcare reform, implementation is difficult. Treating Health Care reminds us of the importance of clarity in the ideas, institutions and interests that are involved in developing health policy.

Some policy fundamentals are established by Professor Deber in the early chapters, where she emphasizes that tradeoffs that must occur among healthcare institutions and interests need to be driven by established ideas or values. Core values or policy objectives such as security, liberty, equity and efficiency are identified. Inherently, there are winners and losers in trading off these values. Lack of unity in health policy is often driven by interests and institutions in the absence of an established policy objective. When this occurs, interests are driven by the concentrated and diffuse advocacy of stakeholders, and institutions (structures designed to make decisions) shape who is and is not at the decision-making table.

The strength of this policy analysis approach is its ability to clarify how likely different options are to achieve an objective. As always, the devil is in the details. Broadly, we may have a goal of achieving better health for the population. However, as Professor Deber details, our definition of health matters. The World Health Organization defines health as a "state of complete, physical, mental and social well-being and not the absence of disease or infirmity." In contrast, our present healthcare system takes a narrower approach and is designed to provide sickness care rather than wellness. Importantly, she emphasizes that the analysis does not decide on the priority assigned to these different objectives or values but rather assesses the options.

Often health policy texts are structured chronologically, with the justification for the unique way Canadians allocate resources in health, being a product of our history. Interestingly, Professor Deber does not take this approach. Rather, the emphasis is on values and simplified, well-accepted policy tools that are fundamental for policy analysts, to bring readers back to basics on how we might systematically make sense of the broad and diverse field that is health policy.

Although the policy analysis "toolkit" that is the foundation for Treating Health Care does not highlight emerging innovation, it is the bridge where policy theory meets practical application. Policy tools available to achieve policy goals can be classified in many ways and involve different degrees of government involvement both within and across ministries, ranging from maintaining status quo to exhortation, expenditure and taxation to regulation and public ownership.

Acknowledgement of the host of tools available in policy opens the discussion to adopting a more wellness-driven approach, integrating the social determinants of health into traditional health policy analysis. This direction is supported by international research that highlights the importance of this broader view of policy analysis and its impact on health. For example, work by Bradley et al. (2010) looked at how a policy tool such as social and health expenditure might influence socio-economic factors experienced, such as income, education, employment and social support networks, when trying to improve a policy objective toward better population health outcomes. Their analysis of US state-level data found that more spending on social services per dollar spent on healthcare services is associated with better population health outcomes. A similar analysis using provincial expenditure data found that this holds true in Canada as well.

The analytical approach outlined by Professor Deber in Treating Health Care aligns interests and institutions with health policy ideas. This approach frames important questions, such as how can we connect the inputs (resources needed to provide healthcare) to the output (health)? Who should be responsible for balancing the supply and demand of workers within the healthcare system? How much should allied health professionals be paid? How can integration (horizontal and vertical) of healthcare services and coordination (continuity of care) be improved? Professor Deber discusses important background on these topics and the need for breaking down silos in healthcare, including who delivers care and how health professionals are determined.

Professor Deber runs through historical context in a remarkably concise way as a means for leading to the important conversation about cost, access and quality that underpins health reform initiatives. Historical context and specifics for how Canada finances and delivers healthcare play a supporting role. This is a refreshing approach to health policy that uncouples the past from the future, empowering those analytically minded to not be satisfied with the "we have always done it this way" approach.

International comparisons are crudely outlined in Treating Health Care, highlighting different approaches to finance and delivery of healthcare. In a simplified and theoretical description, Professor Deber focuses on the social insurance Bismark model developed in Germany, the National Health Service Beveridge model developed in the UK, and the United States modelling a greater emphasis on private payment and provision. Canadians typically have limited understanding of international approaches to health policy, and readers could likely benefit from more depth in this discussion. However, Professor Deber rightly acknowledges that "describing international systems is like trying to hit a moving target," and references are provided for those who are interested in further reading.

Important context for interpreting often-cited comparisons of health system indicators from the WHO, The Commonwealth Fund and the Organisation for Economic Co-operation and Development (OECD) moves the narrative 
beyond the headlines. A critical take-home message is that health policy solutions are often not found in broad comparisons of averages. As Professor Deber notes, "If you have one foot in a pail of boiling water and the other in a pail of ice water, on average, you are comfortable."

She elaborates on the challenges of interpreting averages, noting that variability in coverage and patient experience is influenced by where you live, your living conditions, what type of care you need, where services are delivered, by what provider and what private insurance coverage you have. An example provided is that per capita spending does give a frame for comparison with other countries but lacks the granular information needed for the analysis of options for reform. Understanding that the top $1 \%$ of spenders account for $35 \%$ of healthcare expenditures and that $90 \%$ of the population fell below the mean expenditure for hospital care gives better ability to frame the policy issue. Policy options can then focus on keeping low spenders healthy and effective use of resources for high spenders and vulnerable populations.

In the latter chapters, the policy analysis toolkit is applied to four "pressing issues" for healthcare reform that elaborate on this approach. The pressing issues Professor Deber discusses are areas she identifies as priorities for targeted policy change to improve healthcare. These include four broad themes that are generally recognized as important areas of focus in health policy:

1. make people healthier and help them stay healthy;

2. improve how services are coordinated (service integration) and improve the quality of care, including patient safety;

3. change how we organize our system, including how we pay for care (including who pays for what) and how we deliver it (including doing something about wait lists and access); and

4. become more efficient, to get better value for money.

Professor Deber's discussion of these reforms remains high level but does highlight the role of ideas, institutions and interests with the intent of empowering the reader to apply the concepts to more specific issues in their context.
Despite the merits of policy analysis, resource allocation decisions inherently have winners and losers. Health policy is not exempt. Micro-, meso- and macro-level decisions occur every day, spanning from a patient's lifestyle choices to which provider sees which patient to budget allocation decisions. Professor Deber pushes readers to apply the policy analysis toolkit more broadly and purposefully to attain better population health.

Traditionally, health policy is aimed at regulating the quantity of services provided or availability of diagnostic technologies, drugs and devices. Less progress has been made in focusing on the value of services for patients and payers through approaches introducing competitive procurement mechanisms and alternative finance models, despite the potential to resource more productive hospitals, improve integration and coordination of healthcare services and incentivize prevention strategies. The analytical perspective Professor Deber presents provides a path for improving priority setting and avoiding alternatives that provide little or no value for money. Treating Health Care comes with an empowering prescription to tool up clinicians, patients and families to work collaboratively toward evidence-informed health policy approaches that might help us buy health rather than healthcare. $\mathrm{HQ}$

\section{Reference}

Bradley, E. H., S. Pallas, C.Bashyal, P. Berman and L. Curry. 2010. Guide to Concepts, Determinants, Measurement, and Intervention Design. Retrieved December 31, 2018. <http://siteresources. worldbank.org/HEALTHNUTRITIONANDPOPULATION/ $\mathrm{R}$ e s o u r ces / $281627-1095698140167$ / DevelopingStrategiesforImprovingHealthCareDelivery.pdf $>$.

\section{About the Reviewer}

Dr. Jennifer Zwicker is the director of Health Policy at the School of Public Policy and an assistant professor in the Faculty of Kinesiology, University of Calgary. She is a member of the Owerko Center in the Alberta Children's Hospital Research Institute and the O'Brien Institute of Public Health.

\section{HealthcareQuarterly.com}

